\title{
Study of Impulse Rate and its Types and Measurement by Thump Finger and its Essential Aspects
}

\author{
Muhammad Imran Qadir, Muhammad Faraz Siddique* \\ Institute of Molecular Biology and Biotechnology, Bahauddin Zakariya University, Multan, Pakistan \\ *Corresponding Author: Muhammad Faraz Siddique, Institute of Molecular Biology and \\ Biotechnology, Bahauddin Zakariya University, Multan, Pakistan
}

\begin{abstract}
The main objective of the present study was to corelate likeness of cocomo with the impulse measurement or heart rate. Heart basically is the number of time a heart beats in a minute. Heart is basically a muscle which strengthen the other muscles of body. Normal heart rate varies between 60 to 100. While normaly athletes at rest possess 40 to 60 heart rate. Heart also associated with the emotions and stress conditions. Cocomo is a bisconi many people feel delighted to have cocomo. As it bears sweet taste and different age groups have different views. Heart rate also associated with the age group and body size also blood flow rate normally known as blood pressure. So feelings also have significant impacts on impulse rate. Average impulse rate find out is 76.12 with likeness of cocomo. 79.29 impulse rate dislike cocomo.
\end{abstract}

Keywords: Heart rate, cocomo, impacts.

\section{INTRODUCTION}

Impulse rate is the number of time heart beats per minute, heart rate best measure at rest while lying or siting. If a person possess below $60 \mathrm{bpm}$ doesn't means that there was a heart problem . normally active persons bears $40 \mathrm{bpm}$. While normal impulse rate is 60 to $100 \mathrm{bpm}$. Impulse rate is affected by stress,emotions and age also. 5 to 15 years has $70-100$ impulse rate. 100 impulse rate counted best and considered active. Some peoples take blood pressure medications to normalize their blood pressure and impulse rate.

\section{ProjeCT}

The questionnaire was prepared about measuring pulse rate in a minute and about measuring method.

\section{DISCUSSION AND RESUlT}

Questionniare based study have been given significant outcomes. As average people possess impulse rate and like cocomo whereas average people posses heart rate did not like cocomo. Average 76.12 impulse rate like cocomo.79.29 impulse rate average dislike cocomo.

\section{Material ANd Methods}

Inside of elbow or wrist or side of the neck or yop of the foot and two fingers or thumb. Take two fingers on wrist of hand and measure or count the number of impulse by using senses ina 60 seconds. There should br hert rate between 60 to 100 . Or this can be done in 20 seconds by multiplying by three.

\begin{tabular}{|c|c|}
\hline yes & No \\
\hline Average $=76.12$ & Average79.29 \\
\hline STDEV $=13.32$ & STDEV=12.12 \\
\hline
\end{tabular}

\section{CONCLUSION}

Impulse rate of young students collected. Average impulse rate 76.12 , like cocomo. Average 79.29 dislike cocomo.so its shows likeness and dislikeness average also. 
Development of a 3D Multi-Parameter Method to Evaluate Heart Looping and Chamber Volume in Zebrafish Embryos

\section{REFERENCES}

[1] Urwa Tayyab (2018) from Institute of pure and applied biology, Bahaudin Zakariya University Multan.

[2] Qadir MI, Noor A (2018) Anemias. Rare \& Uncommon Diseases. Cambridge Scholars Publishing. Newcastle, England. ISBN: 978-1-5275-1807-0.

[3] Qadir MI, Javid A (2018) Awareness about Crohn's Disease in biotechnology students. Glo Adv Res J Med Medical Sci, 7(3): 062-064.

[4] Qadir MI, Saleem A (2018) Awareness about ischemic heart disease in university biotechnology students. Glo Adv Res J Med Medical Sci, 7(3): 059-061.

[5] Qadir MI, Ishfaq S (2018) Awareness about hypertension in biology students. Int J Mod Pharma Res, 7(2): 08-10.

[6] Qadir MI, Mehwish (2018) Awareness about psoriasis disease. Int J Mod Pharma Res, 7(2): 17-18.

[7] Qadir MI, Shahzad R (2018) Awareness about obesity in postgraduate students of biotechnology. Int J Mod Pharma Res, 7(2): 14-16.

[8] Qadir MI, Rizvi M (2018) Awareness about thalassemia in post graduate students. MOJ Lymphology \& Phlebology, 2(1): 14-16.

[9] Qadir MI, Ghalia BA (2018) Awareness survey about colorectal cancer in students of M. Phil Biotechnology at Bahauddin Zakariya University, Multan, Pakistan. Nov Appro in Can Study, 1(3): NACS.000514.2018.

[10] Qadir MI, Saba G (2018) Awareness about intestinal cancer in university student. Nov Appro in Can Study, 1(3): NACS.000515.2018.

Citation: Muhammad Faraz Siddique, Muhammad Imran Qadir, "Study of Impulse Rate and its Types and Measurement by Thump Finger and its Essential Aspects”, International Journal of Research Studies in Biosciences, 8(5), pp. 24-25. DOI: https:// doi.org/10.20431/2349-0365.0805005

Copyright: (C) 2020 Authors, This is an open-access article distributed under the terms of the Creative Commons Attribution License, which permits unrestricted use, distribution, and reproduction in any medium, provided the original author and source are credited. 